\title{
JAR1, a Dominant Gene Conferring Resistance to Amphotericin B in Saccharomyces cerevisiae
}

\author{
Joyce Iwema, Katherine Force, and Robin Pals-Rylaarsdam ${ }^{\dagger}$ \\ Biology Department \\ Trinity Christian College \\ 6601 West College Drive \\ Palos Heights, Illinois 60463 USA
}

Received: September 24, 2005

Accepted: November 18, 2005

\begin{abstract}
Infectious diseases are the cause of death for over 1 million people a year in the United States alone. Drug resistance in infectious microbes is an increasing problem. This study focuses on antibiotic resistance in fungal infections, using Saccharomyces cerevisiae as the model of study. Spontaneous mutations in this yeast resulted in a yeast strain with the ability to grow in the presence of the antifungal drug amphotericin B. This yeast isolate, named JAR1, was genetically analyzed to determine how many mutated genes were responsible for the resistant phenotype, and whether the allele was dominant or recessive. The results indicate that the ability of JAR1 to grow in the presence of amphotericin B is due to a single dominant mutation.
\end{abstract}

\section{BACKGROUND}

Bacterial infections are often treated with antibiotic drugs. However, the misuse of antibiotic drugs has caused drug resistant bacteria to become an increasing problem. Antibiotic misuse includes unnecessary antibiotic prescriptions and patients not completing the full course of their prescription, both of which enable the most drug resistant bacteria to survive, replicate, and spread to other hosts.

The study of drug resistance in bacteria has found four major ways that resistance occurs at the molecular level. First, the drug could be destroyed or inactivated. This occurs when the bacteria express enzymes that chemically alter the First, the drug could be destroyed or inactivated. This occurs when the bacteria express enzymes that chemically alter the

\footnotetext{
${ }^{\dagger}$ Correspondence may be addressed electronically to any of the authors:

Joyce.Iwema@trnty.edu,

Katherine.force@trnty.edu,

Rrylaarsdam@trnty.edu

Correspondence may also be mailed to:

Robin Pals-Rylaarsdam, Ph.D.

Trinity Christian College

Biology Department

6601 West College Drive

Palos Heights, IL 60463
}

drug and inactivate it. This type of resistance commonly arises in penicillinresistant strains. A second way that resistance can occur is through the exclusion of the drug from the cell. In this case, the bacterial cell is altered in a way that prevents the antibiotic from penetrating the cell membrane. Thirdly, the binding site for the antibiotic can be altered in the bacterial cell. Many antibiotics act as competitive inhibitors; altering the active site of the inhibited enzyme in a way that allows normal substrates to continue binding but prevents the antibiotic inhibitor from binding is an effective way to resist the drug action. The last known way of resistance in bacteria occurs when some bacteria use membrane pumps to remove the drug from the cell before the antibiotic has a chance to interact with its molecular targets [1]. All of these types of resistance are caused by mutations that alter bacterial physiology so that the drug can no longer exert its effect.

Drug resistance has been studied extensively in bacteria, and is expected to behave similarly in fungi. Like bacterial infections, fungal infections have a great impact on our society. Infectious fungi are a major cause of death in AIDS patients. These infectious fungi act as opportunistic 
infections that affect immuno-suppressed individuals. Infectious fungi also can occur in the form of common external infections such as ringworm and athlete's foot. However, even though fungal infections are common and important, much less is known about the mechanisms of antibiotic resistance in this class of microbe compared with our knowledge of bacterial drug resistance.

The type of fungi used in this research project is the yeast Saccharomyces cerevisiae, which provides a good model of study for several reasons. The genome of the yeast is fairly small. At $14.7 \mathrm{Mb}$, it is 250 times smaller than a genome of a mammalian cell. This smaller genome will simplify our research efforts as we work to clone antibiotic resistance genes. Yeast also has a life cycle that is accommodating for genetic research. It has a life cycle that includes both haploid and diploid phases. This allows for us to mate mutated yeast with wild-type yeast to look at their offspring in order to clearly understand the nature of the mutation in a matter of one generation. Yeast also divide rapidly, which is helpful in obtaining data quickly.

\section{Methods}

\section{a. Yeast culture and media}

Yeast were cultured on solid and in liquid media at $30^{\circ} \mathrm{C}$ using standard aseptic technique. The following media were used: YPD plates $(10 \mathrm{~g}$ yeast extract, $20 \mathrm{~g}$ peptone, $20 \mathrm{~g}$ dextrose, and $20 \mathrm{~g}$ agar in $1 \mathrm{~L}$ of water), YPD liquid medium ( $10 \mathrm{~g}$ yeast extract, $20 \mathrm{~g}$ peptone, and $20 \mathrm{~g}$ glucose in $1 \mathrm{~L}$ of water), $S D$ complete medium $(6.7 \mathrm{~g} / \mathrm{L}$ yeast nitrogen base without amino acids, $20 \mathrm{~g} / \mathrm{L}$ dextrose, and the following amounts of amino acids or nucleosides per liter: $0.188 \mathrm{~g}$ aspartic acid, $0.188 \mathrm{~g}$ glutamic acid, $0.038 \mathrm{~g}$ isoleucine, $0.038 \mathrm{~g}$ methionine, $0.056 \mathrm{~g}$ lysine, $0.056 \mathrm{~g}$ tyrosine, $0.094 \mathrm{~g}$ phenylalanine, $0.688 \mathrm{~g}$ serine, $0.375 \mathrm{~g}$ threonine, $0.281 \mathrm{~g}$ valine, $0.060 \mathrm{~g}$ leucine, $0.020 \mathrm{~g}$ histidine, $0.040 \mathrm{~g}$ tryptophan, $0.020 \mathrm{~g}$ arginine, $0.040 \mathrm{~g}$ uracil, and $0.040 \mathrm{~g}$ adenine), SD complete plates (SD complete medium plus $20 \mathrm{~g} / \mathrm{L}$ agar), and sporulation (spo) plates $(10 \mathrm{~g} / \mathrm{L}$ potassium acetate $\mathrm{C}_{2} \mathrm{H}_{3} \mathrm{KO}_{2}, 1.0 \mathrm{~g}$ yeast extract, $0.5 \mathrm{~g}$ glucose, $20 \mathrm{~g}$ agar, and the amounts of amino acids and nucleosides used for SD complete media).

b. Generating mutants

The yeast strain used for these experiments was MHY501: MAT $\alpha$ his3- $\Delta 200$ leu2-3,112 ura3-52 lys2-801 trp1-1 [2]. This yeast was inoculated in a flask of SD complete medium and was placed in an orbital shaker at $30^{\circ} \mathrm{C}$. Fifteen $\mathrm{mL}$ was later removed from this flask and was exposed to UV light for 15 minutes. Yeast removed from this flask was cultured onto 7 YPD plates with amphotericin $B$ at a concentration of $0.5 \mu \mathrm{g} / \mathrm{mL}$. Untreated yeast was also cultured on a single YPD plate with the same concentration of the antibiotic.

\section{c. Mating}

The wildtype yeast (MHY502, isogenic to MHY501 but mating type MATa) was mated with JAR1, the amphotericin B resistant strain of yeast, to form diploid cells. Diploids were mechanically isolated from an agar plate using a dissecting microscope and micromanipulator. The diploid yeast isolates were sporulated on Spo plates to form tetrads. Individual tetrads were digested with zymolyase $(0.01 \mathrm{U} / \mu \mathrm{L}$ in water) for 10-30 minutes on ice, dissected apart using the dissecting microscope, and haploid cells were aligned in rows to allow genetic analysis of the meiotic offspring of each diploid cell.

\section{d. Exposure to Antibiotic}

Each set of tetrads was analyzed for growth on SD complete agar plates (SD complete containing $20 \mathrm{~g} / \mathrm{L}$ Bacto-agar) and $2.5 \mu \mathrm{g} / \mathrm{mL}$ amphotericin B. A portion of each haploid colony from each dissected tetrad was transferred to sectors of these plates in a manner allowing visualization of individual colonies.

\section{RESULTS AND DISCUSSION}

a. Determining effective concentration of amphotericin B

The experiments that we did involved plating yeast and observing the growth patterns. We used YPD plates with 


\begin{tabular}{|c|c|}
\hline $\begin{array}{c}\text { Amphotericin B Concentration } \\
(\mu \mathrm{g} / \mathrm{mL})\end{array}$ & Growth \\
\hline 0 & + \\
\hline 0.01 & + \\
\hline 0.05 & + \\
\hline 0.5 & - \\
\hline 2.5 & - \\
\hline
\end{tabular}

Table 1. Amphotericin B Concentration

the drug, amphotericin B. Before we could make these plates, we needed to determine which concentration of amphotericin B should be used. We prepared YPD plates at five different amphotericin B concentrations, plated several million yeast cells on the plates, and observed the growth of the yeast (Table 1). Concentrations of $0.5 \mu \mathrm{g} / \mathrm{mL}$ and $2.5 \mu \mathrm{g} / \mathrm{mL}$ prevented growth of the yeast. However, the plates with a lower concentration of amphotericin B still provided an environment that supported the wild type yeast. From these data, we decided to use YPD plates with an amphotericin B concentration of $2.5 \mu \mathrm{g} / \mathrm{mL}$.

\section{a. Isolating amphotericin B-resistant colonies: JAR1}

Next, we plated wild type yeast and yeast exposed to 15 minutes of UV light on amphotericin B plates. This treatment yielded several yeast colonies that were able to grow in the presence of the drug. Interestingly, these colonies appeared on the amphotericin B plates where untreated yeast was plated, signifying the mutation was spontaneous and not caused by exposure to the UV light. We named the first isolated strain JAR1 (Joyce's Amphotericin Resistant strain 1), and analyzed it further genetically.

\section{b. Analyzing JAR1: a dominant mutation}

We first wanted to determine whether JAR1 was a dominant or recessive mutation. To investigate this, we mated JAR1 with an isogenic wild type yeast strain and isolated diploid heterozygote cells using a dissecting microscope and micromanipulator. Figure 1 shows a plate with $2.5 \mu \mathrm{g} / \mathrm{mL}$ Amphotericin B. The top patch is from a WT/WT (wild type/wild type) diploid colony, and shows very little growth with only a few individual colonies emerging from the patch. The other four patches are JAR1/WT diploid colonies which all show good growth in the patches and numerous individual colonies. Wild type yeast does not grow in the presence of amphotericin B, so the growth pattern of the diploid indicates whether the mutation is dominant or recessive. A dominant mutation would cause the diploid heterozygote to grow in the presence of amphotericin B. On the other hand, a recessive mutation would not grow, because the wild type gene would be dominant. The JAR1/WT diploid colonies grew in the presence of the drug, clearly showing JAR1 to be a dominant mutation.

An SD complete plate with 2.5 $\mu \mathrm{g} / \mathrm{mL}$ of amphotericin B plate shows the growth pattern of diploid yeast colonies. The top row shows a patch from a WT/WT colony with very little growth. The second and third rows are JAR1/WT colonies with strong growth in the presence of amphotericin B.

\section{d. Analyzing JAR1: a single mutation}

Next, the JAR1/WT diploid colonies were patched to sporulation plates to induce meiosis and tetrad formation. In the life cycle of yeast a diploid $(2 \mathrm{~N})$ yeast cell

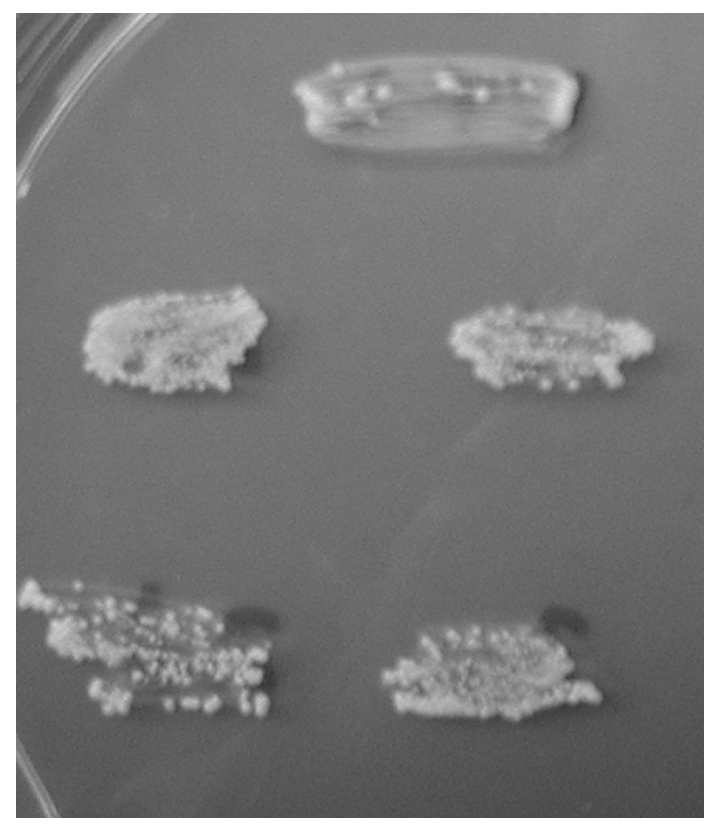

Figure 1. Wild Type and JAR1/WT diploid cells demonstrate that JAR1 is a dominant mutation. 
sporulates to form a tetrad of four haploid cells $(1 \mathrm{~N})$. This process occurs when the yeast senses a loss of glucose and nitrogen. In order to protect itself, the yeast undergoes a meiotic process that produces four haploid cells that contain one copy of each chromosome. This tetrad, enclosed in a protective ascus, waits until the food supply is returned, and then each of the haploid cells re-enters the cell cycle. We used a micro-dissector to separate the four haploid cells from individual asci. Each haploid cell from the tetrad grew into a colony on the rich YPD medium we used for micro-dissection, allowing genetic analyses of the mutation.

For each of 15 tetrads, the haploid colonies were streaked to SD complete plates containing $2.5 \mu \mathrm{g} / \mathrm{mL}$ of amphotericin $B$, and the pattern of amphotericin resistance was recorded. For each of the four haploid colonies from a tetrad, two grew on the plates in the presence of the drug and two did not. A representative plate of haploid cells streaked to SD complete + amphotericin B is shown in Figure 2. The data from the tetrads show a clear 2:2 ratio. The number of haploid colonies that grew in

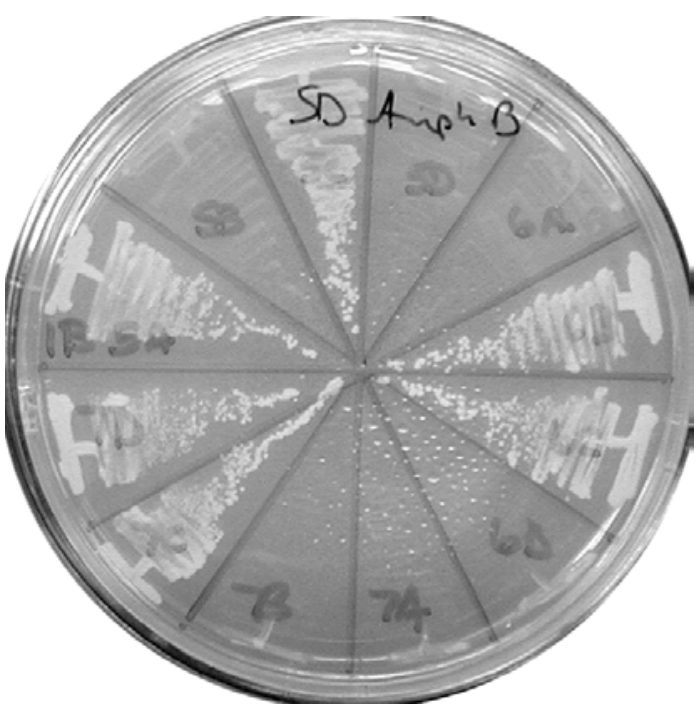

Figure 2. An SD-complete plate with 2.5 $\mu \mathrm{g} / \mathrm{mL}$ Amphotericin B shows the growth ratio of the meiotic offspring of three JAR1/WT diploid colonies. Each diploid colony was sporulated to produce a tetrad of four haploid cells. Each haploid cell was isolated, grown into a colony on YPD agar, and then plated on the photographed plate to produce isolated colonies. A clear 2:2 growth ratio is present.

2A)

$\begin{array}{lll}\begin{array}{c}\text { A } \\ \text { Aa }\end{array} & \\ \text { Genotype } & & \\ \text { A } & \text { Phenotype } \\ \text { A } & \text { R } \\ \text { a } & \text { R } \\ \text { a } & \text { S } \\ & \text { S }\end{array}$

2B)

ab $\underset{A a B b}{x} A B$

$\begin{array}{llllll}\text { Genotype 1 } & \text { Phenotype 1 } & \text { Genotype 2 } & \text { Phenotype 2 } & \text { Genotype 3 } & \text { Phenotype 3 } \\ \text { AB } & \text { R } & \text { AB } & \text { R } & \text { Ab } & \text { S } \\ \text { Ab } & \text { S } & \text { AB } & \text { R } & \text { Ab } & \text { S } \\ \text { aB } & \text { S } & a b & S & a B & \text { S } \\ \text { ab } & \text { S } & \text { ab } & \text { S } & \text { aB } & \text { S }\end{array}$

Table 2. 2A) The expected phenotypic ratio of a single dominant mutation in gene "A". Capital letters indicate dominant alleles; lower-case letters indicate recessive alleles. $R=$ resistant; $S=$ susceptible. The possible genotypes for each haploid offspring of the diploid cell listed at the top are listed along with their resulting phenotype. 2B) The expected phenotypic ratio for a double mutation in genes $A$ and $B$ leading to the resistant phenotype. Note that each set of two columns describes one possible assortment of two heterozygous genes during a meiotic event. 
the presence of amphotericin B indicates the number of mutations that caused the trait of resistance. If resistance was caused by only one gene mutation we would expect to see a ratio of 2 resistant to 2 susceptible haploid cells in every tetrad (Table $2 \mathrm{~A}$ ). If resistance is caused by two mutations working together, then the growth pattern would be more complicated, resulting in different ratios depending on the meiotic segregation of the two alleles (Table 2B). Taken together, our data indicate that the JAR1 phenotype of amphotericin B resistance is caused by only one mutation.

\section{CONCLUSION}

In conclusion, the spontaneously mutated strain, JAR1, exhibits resistance to amphotericin B caused by a single, dominant mutation. We now plan to make a genomic library from JAR1 DNA, and clone the JAR1 gene by introducing plasmids from the library into WT yeast. The presence of the JAR1 gene will confer amphotericin B resistance onto the yeast in a plasmid- dependent manner. We will then isolate the plasmid, sequence it, and determine the identity of the JAR1 gene. Identification of this mechanism of fungal antibiotic resistance will further our knowledge of drug resistance mechanisms in this medically important class of microbes.

\section{ACKNOWLEDGMENT}

This research was supported in part by a Trinity Christian College Vander Velde Junior Scholar award to J. Iwema and K. Force.

\section{REFERENCES}

1. Tortora, Gerard J., Berdell R. Funke and Christine L. Case. Microbiology. $7^{\text {th }}$ edn. 2001.

2. Chen, P., Johnson, P., Sommer, T., Hentsch, S., and Hochstrasser, M. (1993) "Multiple Ubiquitin-Conjugating Enzymes Participate in the In Vivo Degradation of the Yeast MAT $\alpha 2$ Repressor," Cell 74: 357-369.

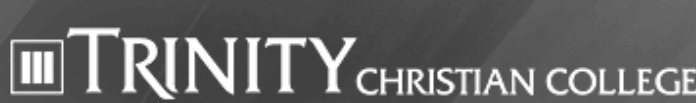

MOMENT U M FOR L I F E

Trinity Christian College, 6601 W. College Drive, Palos Heights, Illinois USA 60463 USA 1.866.TRIN.4.ME $\bullet$ http://www.trnty.edu/

\section{ABOUT TRINITY}

Trinity Christian College is a four-year liberal arts college located in Palos Heights, Illinois, a suburb twenty miles southwest of Chicago. Since its founding in 1959, Trinity has provided its students with an excellent Christian higher education in the Reformed tradition, offering majors in the arts,

humanities, social sciences, and natural sciences, as well as professional programs in accounting and business administration, nursing, education, computer science, premedicine, social work, and pre-law.

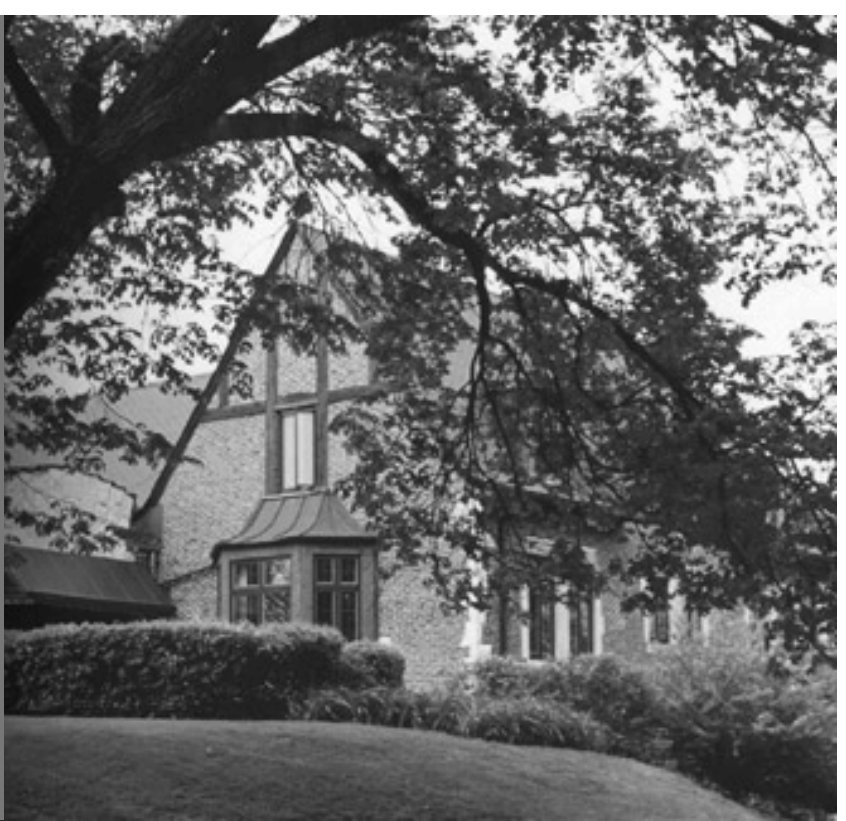




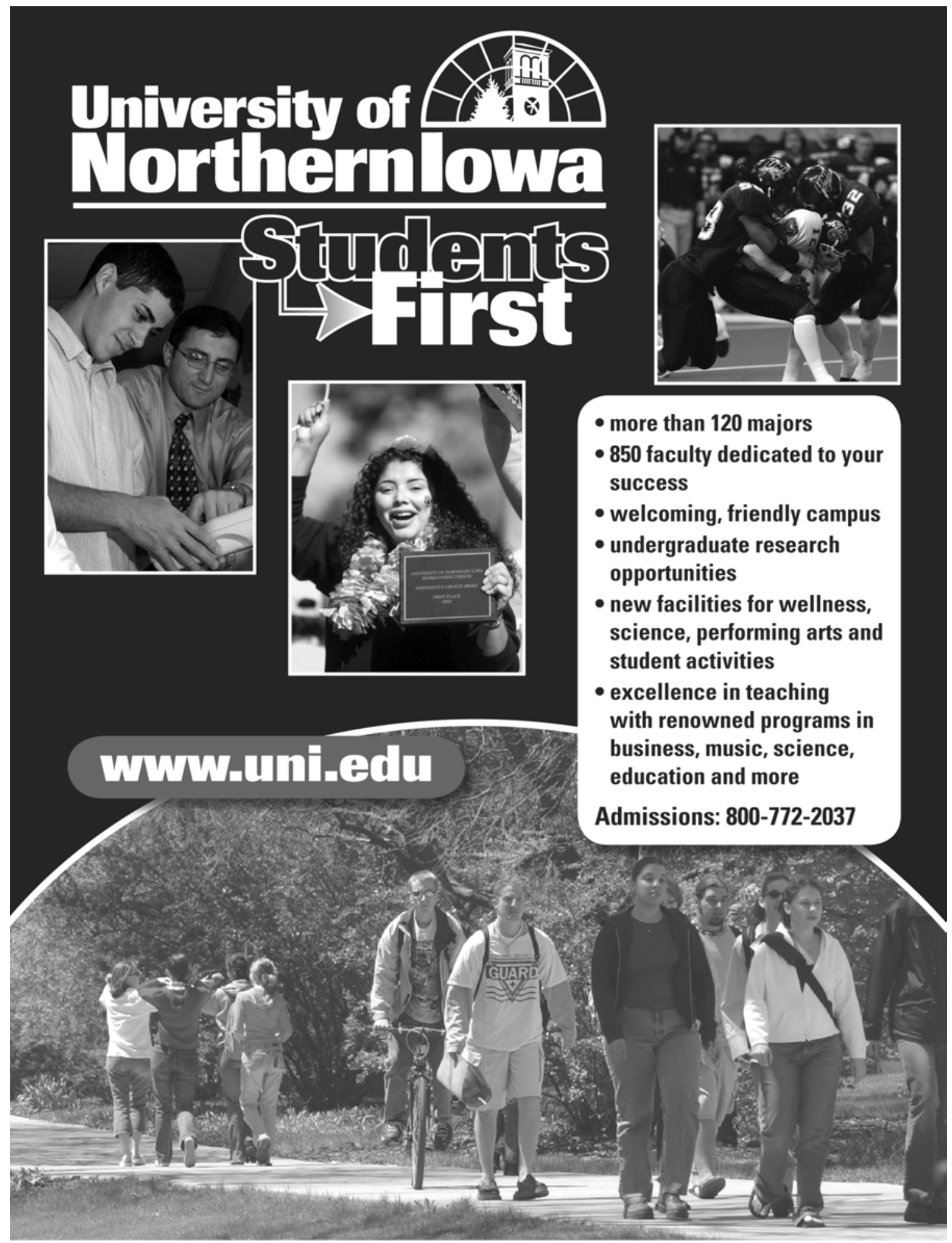

